\title{
DAS POLÍTICAS DE GOVERNO À POLÍTICA DE ESTADO: REFLEXÕES SOBRE A ATUAL AGENDA EDUCACIONAL BRASILEIRA
}

\author{
DALILA ANDRADE OLIVEIRA*
}

\begin{abstract}
RESUMO: $\mathrm{O}$ artigo discute as políticas educacionais na atualidade, buscando analisar o contexto que engendra a Conferência Nacional de Educação (CONAE), sua principal proposta e os desdobramentos a partir de sua realização até a apresentação do Projeto de Lei n. 8.035/10 que propõe o novo Plano Nacional de Educação (PNE). Identifica como principal proposição da referida Conferência a constituição de um Sistema Nacional de Educação. Procura também compreender as razões que poderiam explicar tal proposição, após duas décadas de reformas que apontam para a descentralização e desregulamentação, e os conceitos que podem orientar a organização sistêmica em educação. Por fim, o texto busca explorar a relação entre políticas de governo e política de Estado, trazendo algumas indagações sobre os riscos e as possibilidades de mudança no plano legal que poderiam enfrentar os principais problemas apontados para a educação brasileira na atualidade, demonstrando a contradição entre a proposição de sistema defendida na CONAE e sua ausência no projeto de lei do novo PNE.
\end{abstract}

Palavras-chave: Política educacional. Sistema Nacional de Educação. Gestão da educação.

\section{From FEDERAL to STATE GOVERNMENT POLICIES: REFLECTIONS ON THE CURRENT BRAZILIAN EDUCATION AGENDA}

ABSTRACT: This paper discusses the current education policies in order to analyze the context that gave birth to the National Education Conference (CONAE), its main proposal, and what happened after it, until the bill (PL 8.035/10) on the new National Education Plan (PNE) was presented. The principal objective this Conference was to create a national education system. The text tries to understand the reasons for such a proposition, after two decades of reforms towards decentralization and deregulation, as well as the concepts that can guide the organization of the education system. Finally, it explores the relationship between Federal government policies and State policy, questioning the challenges and possibilities of changes on the legal plan that the current key problems in Brazilian education could have to face. It thus demonstrates a huge contradiction since the system advocated at the CONAE was not included in the bill proposing the new PNE.

Key words: Education policy. National Education System. Education management.

\footnotetext{
* Doutora em Educação e professora titular do Programa de Pós-Graduação e da Faculdade de
} Educação da Universidade Federal de Minas Gerais (UfMG). E-mail: dalila@fae.ufmg.br 


\title{
DES POLITIQUES DE GOUVERNEMENT À LA POLITIQUE D'ÉTAT: RÉ-
} FLEXIONS SUR L'AGENDA EDUCATIONNEL BRÉSILIEN

\begin{abstract}
RÉSUMÉ: Cet article discute les politiques éducationnelles en vigueur en cherchant à analyser le contexte qui a engendré la "Conférence Nationale d'Éducation" (Conferência Nacional de Educação - CONAE), sa principale proposition et ses prolongements, de sa réalisation à la présentation du Projet de Loi (PL 8.035/10) proposant le nouveau Plan National d'Éducation (Plano Nacional de Educação - PNE). Comme la proposition principale de cette Conférence était la constitution d'un système national d'éducation, ce texte cherche à comprendre les raisons qui pourraient expliquer qu'elle ait été proposée après deux décennies de reformes dirigées vers la décentralisation et la déréglementation ainsi que les concepts qui pourraient orienter l'organisation du système éducatif. Finalement, il explore le rapport entre les politiques de gouvernement et les politiques d'État pour évaluer les risques et possibilités de changement sur le plan légal que les principaux problèmes de l'éducation brésilienne pourraient avoir à affronter, rehaussant ainsi une contradiction puisque la proposition de système soutenue à la CONAE n'apparaît pas dans le projet de loi sur le nouveau PNE.
\end{abstract}

Mots-clés: Politique éducationnelle. Système national d'éducation. Gestion de l'éducation.

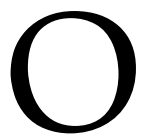

presente artigo pretende discutir o atual momento da política educacional brasileira em que começa a tramitar no Congresso o Projeto de Lei n. 8.035/10, que irá instituir um novo Plano Nacional de Educação (PNE). O objetivo é analisar esse momento à luz das políticas mais recentes que interferiram na educação brasileira e os desafios atuais trazidos pela nova condição que o país passou a ocupar no cenário internacional. O texto propõe-se a discutir a proposta de criação de um Sistema Nacional de Educação, previsto em lei, a partir dos pressupostos que sustentam a organização sistêmica.

No último ano de mandato do presidente Luiz Inácio Lula da Silva, foi realizada a Conferência Nacional de Educação (CONAE), que significou um amplo movimento financiado e, em grande medida, ensejado pelo Ministério da Educação. A referida Conferência, ocorrida em Brasília, entre os dias 28 de março e $1^{\circ}$ de abril de 2010, pretendeu ser um processo democrático aberto pelo Poder Público que possibilitasse a ampla participação de setores ligados à educação brasileira nos seus distintos níveis, modalidades, interesses e finalidades, já que pautou a educação escolar, da educação infantil à pós-graduação. A conAe foi precedida de conferências municipais, regionais e estaduais que, a partir de um documento de referência, possibilitou o debate sobre o futuro da educação brasileira para os próximos dez anos, envolvendo professores e outros profissionais da educação, estudantes, pais, gestores, enfim, diferentes segmentos organizados em torno da educação.

O tema central da ConAE foi "Construindo um Sistema Nacional Articulado de Educação: Plano Nacional de Educação, suas Diretrizes e Estratégias de Ação". 
Esse tema é revelador de um sentimento compartilhado por distintos setores que compuseram a comissão organizadora da conAE. ${ }^{1}$ Entretanto, mais que revelar os sentimentos e sentidos dos diferentes setores que compuseram tal comissão, esse tema expressa um movimento que começa a tomar corpo na educação brasileira no final do primeiro mandato do presidente Lula, a despeito de ter-se constituído em ponto de referência para a elaboração do primeiro projeto de Lei de Diretrizes e Bases para Educação Nacional, após a promulgação da Constituição Federal da República de 1988, em que as entidades de estudos e pesquisas em educação exerceram significativo protagonismo, atuando no âmbito do Fórum Nacional em Defesa da Escola Pública (fNDeP).

\section{Antecedentes: o contexto que engendrou a CONAE}

O contexto que antecedeu a ConAE foi marcado por rupturas e permanências em relação ao período anterior ao governo Lula, ${ }^{2}$ mais especificamente à década de 1990, em que por oito anos esteve à frente do Estado brasileiro um governo encabeçado pelo sociólogo Fernando Henrique Cardoso (FHC), que promoveu amplas mudanças no conjunto das políticas públicas e sociais.

O governo FHC (1995/2002) teve como um dos seus grandes feitos a garantia da estabilidade econômica alcançada pelo Plano Real. ${ }^{3}$ Tal estabilidade lhe deu sustentação para empreender um conjunto de reformas no âmbito do Estado, buscando sua racionalização e modernização. Essa reforma foi constituída de privatização de empresas estatais e mudanças na forma de gestão das políticas públicas. A desregulamentação da administração pública federal foi perseguida por meio da descentralização, o que em certa medida atendia também aos anseios de outros setores, expressos na Constituição Federal de 1988, que alterou significativamente o Pacto Federativo brasileiro.

A Constituição Federal de 1988 desenhou uma ordem institucional bastante distinta daquela então vigente. Considerado um dos sustentáculos básicos da democracia brasileira, o arranjo federativo adotado implicou mudanças radicais. Há quem considere que o modelo anterior foi inteiramente invertido (Sadek, 2000).

Os constituintes, orientados por uma concepção específica de democracia, optaram por mecanismos de participação popular que levaram à descentralização de poder e de recursos. A descentralização foi apresentada como a alternativa de gestão das políticas públicas e sociais, favorecendo a fragmentação e, consequentemente, ampliando o número de atores políticos. Nesse arranjo, governadores e prefeitos adquiriram papel político de primeira grandeza, sem, contudo, anular ou diminuir o poder de antigas lideranças. Segundo Sadek (2000), o texto constitucional retratou 
a preocupação muito mais com a participação popular que com a obtenção de um consenso social sobre o que deve ser conseguido com a descentralização, resultando em que o fortalecimento dos governos subnacionais impeça que o governo federal reúna sozinho as condições para propor e efetivar políticas que objetivem a solução de problemas nacionais. Da tensão entre os interesses nacionais e subnacionais foi gerado um federalismo de todo singular. Isto é, a norma legal que preceitua a descentralização não é entendida como uniformizadora, garantindo que todos os estados e municípios desfrutem o mesmo poder. Ao contrário, o jogo político desenvolve-se no interior de processos extraconstitucionais que refletem a força relativa dos distintos atores políticos, particularmente dos governadores, dos prefeitos, e seus controles sobre as bancadas de deputados e os cargos no Executivo Federal. Dessa forma, o espaço da negociação passou a desempenhar papel decisivo. Nesse processo, procurou-se redefinir o tradicional "clientelismo" que, de alguma maneira, passou a conviver com padrões provenientes de uma sociedade mais democrática (Sadek, 2000).

Apesar de parecer responder no plano da gestão política aos preceitos constitucionais, ou seja, de estar amparado pela Constituição para realizar as mudanças pretendidas que, em última instância, buscavam reorientar a relação entre o Estado e a sociedade civil, ou governo e cidadãos, as reformas ocorridas no período FHC foram na contramão de muitos direitos e garantias conquistados na mesma Constituição Federal de 1988. No que se refere à educação, os exemplos são vários. A ampliação do direito à educação para todos os brasileiros de seu nascimento à conclusão do ensino médio foi comprometida pela Emenda n. 14 de 1996, que focalizava o ensino fundamental. As reformas educacionais dos anos de 1990, no Brasil, tiveram como grande foco a gestão, buscaram por meio da descentralização administrativa, financeira e pedagógica promover a ampliação do acesso à educação básica no país a partir de uma lógica racional, que tinha como paradigma os princípios da economia privada.

O conjunto de reformas implantadas na educação brasileira nesse período resultou na reestruturação da educação escolar nos seus aspectos relativos à organização, à redefinição dos currículos por meio dos Parâmetros Curriculares Nacionais (PCN), à avaliação pelo incremento ao Sistema Nacional de Avaliação da Educação Básica (SAEB) e depois o Exame Nacional de Cursos (ENC), à gestão e ao seu financiamento, melhor exemplificado pela criação do Fundo de Manutenção e Desenvolvimento do Ensino Fundamental e de Valorização do Magistério (FundEF). Especialmente na educação básica, as mudanças realizadas redefiniram sua estrutura. As alterações na legislação educacional brasileira consumaram essa nova reconfiguração, tendo como expressão maior a Lei de Diretrizes e Bases da Educação Nacional (LDB) n. 9.394/96. 
Esse movimento de reformas levado a termo no Brasil pelo governo de FHC acompanhou a tendência em nível mundial que apontava na direção de maior flexibilidade na gestão, maior autonomia às escolas e maior responsabilização dos docentes. ${ }^{4}$ A descentralização administrativa, financeira e pedagógica foi a grande marca dessas reformas, resultando em significativo repasse de responsabilidades para o nível local, por meio da transferência de ações.

Assim, as reformas realizadas no Brasil durante o governo de FHC, que teve no decorrer de seus dois mandatos um só ministro da Educação, Paulo Renato de Souza, determinaram novas formas de financiamento, gestão e avaliação da educação básica, conformando uma nova regulação assentada na descentralização e em maiores flexibilidade e autonomia local. Essas mudanças foram determinantes de novas relações entre as diferentes esferas administrativas na matéria educacional, especialmente entre União e municípios. Muitos elementos trazidos por essas reformas foram duramente criticados pelos movimentos sociais que estiveram na base eleitoral do presidente Lula.

Ao final do governo FHC, a educação no Brasil vivia um processo fragmentado de gestão, contendo uma profusão de programas sociais e educativos que buscavam atender a públicos focalizados, revelando grande dispersão de políticas temporárias que se afirmavam mais como políticas de governo que de Estado, cujas bases institucionais de controle social não estavam definidas. Como exemplo, podemos lembrar o Programa Alfabetização Solidária, que era a política de governo para enfrentar um dos mais sérios problemas deste país - altos índices de analfabetismo - por meio de uma organização não governamental (oNG) gerida pela primeira-dama à época, a antropóloga Ruth Cardoso. Ao final do governo FHC, é possível considerar que a educação nacional se encontrava em um quadro de (des)sistematização, para designar uma orientação de governo na contramão do que se pode considerar um sistema, ou seja, uma organização da educação nacional fragmentada, segmentada, flexível e dispersa, o que não contribui para estabelecer bases de cooperação, integração e coesão entre os entes federativos e menos ainda entre os indivíduos na sociedade.

\section{Mudança de rumos na política educacional do governo Lula}

Os primeiros anos do governo Lula foram marcados muito mais por permanências que por rupturas em relação ao governo que o antecedeu. Os dois primeiros-ministros da Educação não chegaram a estabelecer uma agenda que se contrapusesse à anterior. Apesar das tentativas do Ministério da Educação nesses primeiros anos de imprimir nova marca à política educacional em curso, no geral observou-se a mesma fragmentação e descontinuidade da década passada. Os de- 
sacertos iniciais foram muitos e, apesar das promessas de campanha, muito pouco foi alterado neste sentido até o final do seu primeiro mandato. É possível considerar assim que, em certa medida, o primeiro mandato de Lula foi caracterizado mais pela promoção de políticas assistenciais e compensatórias por meio de programas sociais desenvolvidos para público-alvo específico, ${ }^{5}$ os mais pobres, que pela ampliação de políticas e ações que assegurassem os interesses universais inscritos na Constituição Federal de 1988. Foram poucas as políticas regulares, de caráter permanente, dirigidas ao conjunto da população, na educação nesses primeiros anos de governo.

O Plano de Desenvolvimento da Educação (PDE) pode ser considerado a primeira grande iniciativa do ministro Fernando Haddad, buscando uma reorientação de rumo para a educação no governo Lula. Constituindo-se na reunião de dezenas de programas que abarcam da educação básica - compreendendo suas etapas e modalidades - à educação superior, tal iniciativa procurou dar direção à política educacional no país, tendo como grande timoneiro o governo federal. O PDE, por meio de parcerias com os municípios, foi desenhando uma arquitetura política que valoriza a dimensão da governança entre os entes federativos, entre estes e as instituições da sociedade civil, apelando para "a responsabilização e mobilização de todos os agentes públicos envolvidos com a educação" (Brasil, 2008). O MEc buscou instaurar um regime de colaboração que propiciasse a repartição de competências e responsabilidades e fizesse subir os indicadores educacionais, sobretudo no que se refere à educação básica. Essa iniciativa pode ser percebida como a busca de uma orientação comum que propiciasse a integração da educação nacional, apesar dos aberrantes desequilíbrios regionais que conhecemos. É, ao mesmo tempo, uma busca de resgatar o protagonismo exercido pelo governo federal em épocas passadas, apesar das contradições que revelam possibilidades e limites entre o nacional e o federal.

Por meio do Programa de Ações Articuladas (PAR), o governo federal buscou, por meio do Ministério da Educação, a adesão dos municípios a uma política orientada pela elevação dos índices de desempenho dos alunos da educação básica no Brasil, cuja referência utilizada foi o Índice de Desenvolvimento da Educação Básica (IDEB). Criado em 2007, о IDEB passou a ser a principal referência do governo para aferir a qualidade na educação. O IDEв mede o desempenho do sistema, estabelecendo uma escala que vai de zero a dez. O índice, inspirado no PISA, ${ }^{6}$ foi elaborado pelo Instituto Nacional de Estudos e Pesquisas Educacionais Anísio Teixeira (INEP/MEc). A fixação da média seis a ser alcançada em 2022 considerou o resultado obtido pelos países da Organização para a Cooperação e o Desenvolvimento Econômico (ocDE), quando aplicada a metodologia do IDEB em seus resultados educacionais. Seis foi a nota obtida pelos países desenvolvidos que ficaram entre os 20 melhores colocados do mundo. ${ }^{7}$ 
A partir da análise dos indicadores do IDEB, o MEC ofereceu apoio técnico e financeiro aos municípios com índices insuficientes de qualidade de ensino. $\mathrm{O}$ aporte de recursos deu-se a partir da adesão ao "Compromisso Todos pela Educação" e da elaboração do PAR. Segundo dados do próprio MEC, a adesão dos municípios foi absoluta. ${ }^{8}$ Pode-se então considerar que o MEc buscou realizar e implementar uma política de Estado ao reunir programas de governo e atribuir orientação, integração e estabilidade à organização da educação nacional.

Considera-se que políticas de governo são aquelas que o Executivo decide num processo elementar de formulação e implementação de determinadas medidas e programas, visando responder às demandas da agenda política interna, ainda que envolvam escolhas complexas. Já as políticas de Estado são aquelas que envolvem mais de uma agência do Estado, passando em geral pelo Parlamento ou por instâncias diversas de discussão, resultando em mudanças de outras normas ou disposições preexistentes, com incidência em setores mais amplos da sociedade.

Ainda que os objetivos perseguidos sejam discutíveis do ponto de vista do paradigma adotado - a eficácia do sistema -, a educação nacional passa a ser orientada na mesma direção, sendo a qualidade da educação básica referenciada no IDEB. O grande problema enfrentado pela educação básica - resultante da divisão de competências entre os entes federativos, que atribui a responsabilidade para com a educação infantil e o ensino fundamental prioritariamente aos municípios e o ensino médio aos estados, restando à União apenas a ação supletiva - persiste e é, ao mesmo tempo, o que possibilita essa política ambivalente empreendida pelo MEc. Por um lado, o MEC tem procurado promover uma política nacional de condução e orientação da educação básica, envolvendo os estados e os municípios e setores da sociedade civil, e buscando recuperar certo protagonismo perdido na definição das políticas educativas em âmbito nacional pelas reformas ocorridas nas décadas passadas. Por outro, reduz as possibilidades de autonomia e autodeterminação dos governos subnacionais.

Iniciativa com a mesma finalidade - recuperar a direção, o papel protagonista do governo federal em educação - pode ser observada ainda na atuação marcante que teve esse ministério na aprovação da lei que estabelece o Piso Nacional de Salários para os professores de educação básica, bem como na instituição do Fundo de Manutenção e Desenvolvimento da Educação Básica e de Valorização dos Profissionais da Educação (FUNDEB); sendo este um fundo de financiamento que cobre a educação básica - compreendendo suas três etapas: educação infantil, ensino fundamental e ensino médio e que pode ser considerado um avanço no sentido de que tenta corrigir as falhas que eram apontadas no FUNDEF, apesar de persistirem os desequilíbrios entre os estados no que se refere ao financiamento da educação básica. 


\section{O sistema nacional articulado: a cONAE como política de governo e o PNE como política de Estado}

A iniciativa acima mencionada do ministro Fernando Haddad de estabelecer como eixo de sua política (ou gestão) o PDE, criado por meio de um decreto, pode nos indicar a tentativa de preenchimento de um espaço vazio, ou de lacunas deixadas pelo Plano Nacional de Educação até então vigente, Lei n. 10.176/01. A pouca eficácia do PNE (2001-2010) em orientar a educação nacional pode ter facilitado a iniciativa de um governo de adotar suas políticas no lugar em que deveria seguir as do Estado. A aprovação do PNE (2001-2010) ocorreu em processo turbulento de tramitação e com idas e vindas e muitos embates entre governo e setores organizados em defesa da educação. Ao final, o texto aprovado resultou em atrasos em relação a conquistas importantes já inscritas na educação brasileira e foi bastante criticado como limitado pelos setores organizados da sociedade em defesa da educação pública, tendo recebido muitos vetos pelo então presidente FHC, que acabaram por comprometer suas metas e objetivos.

Na ausência de uma legislação nacional que estabelecesse o Sistema Nacional de Educação no Brasil, sua estrutura, funcionamento e orientação, caberia ao PNE o lugar de referência legal da educação em todos os níveis e modalidades. Contudo, a força de lei que deveria ter o PNE (2001-2010) não se fez cumprir.

Faltando menos de um ano da data de seu encerramento, a realização da coNAE reunia contribuições de amplos setores organizados para a elaboração de um documento de referência para o próximo pNe (2011-2020). O lema da Conferência, conforme já mencionado, era "Construindo um Sistema Nacional Articulado de Educação: Plano Nacional de Educação, suas Diretrizes e Estratégias de Ação". Que razões levariam amplos setores do público ao privado, do laico ao religioso, do profissional ao patronal, entre outros, a se juntarem na defesa da construção de um Sistema Nacional de Educação?

Por que o novo PNe deveria trazer em seu bojo o Sistema Nacional de Educação? A resposta a essas indagações pode estar nos obstáculos que o regime federativo impõe à gestão e organização da educação, na pouca integração revelada entre estados e municípios, na persistência de desigualdades e desequilíbrios históricos entre regiões, na fragmentação entre as redes públicas nos seus distintos níveis (municipais, estaduais e federal).

Talvez a primeira pergunta que devamos fazer quando se discute a questão seja: em que medida os sistemas escolares podem afetar positivamente a integração e a coesão das sociedades e com que mecanismos e em que condições?

Segundo Dubet, Duru-Bellat e Vérétout (2010), o termo “integração" refere-se à estrutura pela distribuição objetiva das posições sociais que a escola pode realizar. 
Sendo assim, a integração promovida pelo sistema relaciona-se diretamente com os níveis de desigualdade social e escolar, as taxas de emprego e desemprego, as transferências sociais, o nível socioeconômico dos alunos. Já a coesão, de acordo com os mesmos autores, é definida por atitudes, valores e disposições favoráveis à cooperação, à confiança e à tolerância. Contudo, integração e coesão nem sempre andam juntas.

As sociedades e seus sistemas escolares são comumente comparados em relação aos seus níveis de integração, mais factíveis de serem medidos e averiguados. A integração de uma sociedade depende do papel que exerce o Estado em relação aos seus cidadãos, ou seja, as políticas públicas e sociais que desenvolve e põe em ação. Assim, a integração de um país é maior ou menor dependendo das políticas de saúde, segurança, previdência, regulação das relações de trabalho, entre outras que o Estado promove. As desigualdades sociais e de renda, bem como outras variáveis, tais como o tamanho do país, sua dimensão territorial e população, também interferem na integração, tornando-a mais complexa. Da mesma forma, a escola que escolariza seus alunos por longo período e de maneira comum é mais integrada que aquela que os seleciona precocemente e os divide e classifica em diferentes posições.

A coesão é definida por valores e atitudes, tradições culturais e históricas. É do grau de coesão que depende o sentimento de pertencimento social, papel atribuído aos sistemas escolares e tarefa atribuída aos professores para desenvolver em seus alunos, na constituição dos Estados modernos. A noção de coesão é hoje imposta como imperativo pelas agências internacionais e por organismos vinculados à oNU, preocupados com a governance nas sociedades mais fragmentadas. Esses organismos têm defendido o desenvolvimento da coesão como ferramenta estratégica para a governabilidade dos sistemas. A coesão é diferente e complementária à noção de integração: ao passo que esta pressupõe um sistema, a coesão comporta um conjunto de valores, representações, de crenças, que desenvolve o civismo, a solidariedade, a confiança em si, nos outros e nas instituições. São os vínculos, mais que as posições sociais, que asseguram a densidade e a unidade da vida social. Ela interessa à escola pelos valores transmitidos.

Dubet, Duru-Bellat e Vérétout (2010) advertem que as sociedades mais integradas não são necessariamente as mais coesas. Observam que sociedades que são pouco integradas, como, por exemplo, os Estados Unidos da América (EUA), podem ser bastante coesas. Assim como sociedades bastante integradas podem ser pouco coesas, como é o caso da França. Com os sistemas escolares, pode-se observar a mesma relação, ou seja, há sistemas muito integrados e pouco coesos e o contrário, sistemas muito desiguais e bastante coesos. Da mesma forma, não se evidencia relação direta entre o grau de integração e coesão das sociedades e dos sistemas. Assim como se pode ver sociedades em que as desigualdades sociais são fortes e em seus sistemas escolares as 
desigualdades não são relevantes, e o contrário. Tudo isso depende do encaixe das escolas na sociedade: a função atribuída aos diplomas e o impacto deles na distribuição de posições sociais. A relação estreita entre diplomas e emprego deposita na escola a função de promover justiça social minimizando as desigualdades sociais por meio da fragmentação educativa. Na sociedade em que esses vínculos são menos fortes, em que se observa a existência de outros sistemas e mecanismos de distribuição de posições sociais, como os sistemas de formação e qualificação de força de trabalho, a pressão pela escola é menor. Afinal, a educação escolar é um bem relativo.

Refletindo sobre a educação brasileira, sobre o papel que poderia exercer o Sistema Nacional de Educação na integração e coesão deste país, observa-se que nos dois aspectos há muito a fazer. A pouca integração observada no sistema federativo brasileiro e os entraves à real repartição de obrigações e de recursos tributários põem em risco a colaboração pretendida entre os entes federados. Além disso, a crise observada em nossas escolas públicas, frequentemente constatada nos depoimentos dos docentes, que identificam como seus sintomas a indisciplina e o desinteresse dos alunos, os maus tratos que dão à escola e aos professores, as constantes evidências de violência na escola podem refletir o baixo nível de coesão de nosso sistema escolar. O sentimento de pertencimento a um grupo, de compartilhamento de um mesmo coletivo que tem regras comuns, valores e atitudes é indispensável não só aos alunos, mas, sobretudo, aos profissionais. A coesão de um sistema escolar é vital para seu desenvolvimento e melhoramento.

\section{Os desafios atuais da educação brasileira e o PNE: para onde cami- nham as políticas de Estado?}

Têm sido apontados com frequência como principais desafios para a educação brasileira resultantes da nova posição que o país vem alcançando nos últimos anos no cenário político mundial o aumento do nível de escolarização da população e a melhoria do desempenho dos alunos.

Nos últimos anos, o Brasil conseguiu diminuir de forma significativa o número de famílias que vivem em condição de extrema pobreza. Segundo dados do Instituto de Pesquisas Econômicas Avançadas (IPEA), a proporção da população brasileira vivendo abaixo da linha de pobreza está em forte queda desde 2003. Contudo, o país permanece sendo apontado como um dos mais injustos do mundo. De acordo com o Relatório do Programa das Nações Unidas para o Desenvolvimento Humano (PNUD), divulgado em julho de 2010, o Brasil tem o terceiro pior índice de desigualdade no mundo. A distância entre pobres e ricos em nosso país permanece abismal, comparando-se com países como Haiti e Tailândia. Essas desigualdades se refletem diretamente na educação. 
Apesar dos avanços obtidos nos últimos anos, a população brasileira permanece vergonhosamente pouco escolarizada. Segundo dados da PNAD de 2010, a taxa de analfabetismo absoluto da população com 15 anos ou mais é de 9,7\%. Considerando o analfabetismo funcional, essa taxa sobe para $20,3 \%$. Constatou-se aumento na taxa de escolarização das crianças de 4 e 5 anos, de 70,1\% em 2007 para 72,8\% em 2008. Em números absolutos, mais 73 mil crianças desse grupo etário entraram na escola no período, indo de 4,124 milhões para 4,197 milhões de estudantes. Nas demais faixas etárias, houve queda: de 30,9\% (7,3 milhões) para 30,5\% (7,082 milhões) de 18 a 24 anos, e de 5,5\% para 5,3\% (5,83 milhões para 5,771 milhões) para 25 anos ou mais. ${ }^{9}$ Mesmo com esse crescimento verificado da taxa de escolarização da população nas faixas etárias consideradas, ainda são muitos os desafios para alcançarmos indicadores sociais satisfatórios.

São enormes as dificuldades e complexidades para modificar os padrões de funcionamento dos sistemas educativos; isso é sabido em qualquer realidade. No caso brasileiro, dados os aspectos já mencionados da organização federativa do Estado, tais dificuldades revelam-se desafios ainda maiores. Por mais que as duas décadas passadas tenham trazido mudanças na organização da educação que resultaram em maior cobertura, em particular vale lembrar os desafios colocados pela ampliação da obrigatoriedade escolar - de 4 a 17 anos -, trazida com a Emenda n. 59, e a introdução de procedimentos e instrumentos mais democráticos de gestão, tais mudanças não conseguiram modificar significativamente os resultados de aprendizagem dos alunos.

O contexto de reformas instaurado nos anos de 1990, legitimado pela crise da escola ou pelo declínio de uma forma escolar canônica de socialização definida como um programa institucional, como o define Dubet (2004), criou um ambiente propício à mudança ou mesmo à inovação que, em muitos casos, representou a negação de valores, culturas e tradições constituintes do ambiente escolar e do ofício docente. Não se trata de defender aquela escola autoritária que, como afirmava Fernandes (2008), mais se aproximava de instituições punitivas ou carcerárias que da pedagogia do aprender fazendo, mas de recuperar a memória histórica dos sujeitos que constituíram essas instituições a partir de suas experiências. Esse clima, somado ao modelo de gestão implantado a partir dessas reformas - maior flexibilidade, descentralização e desregulamentação -, contribuiu para a dispersão de experiências e modelos de organização escolar e de descontinuidades de políticas nos âmbitos estaduais e municipais; mais uma vez as políticas eram de governo e não de Estado. Os riscos dessa dispersão são justamente contribuir ainda mais para o quadro de fragmentação a que se assiste na educação básica brasileira.

Cunha (1991), analisando a descontinuidade das políticas educacionais, mostranos que esse fenômeno é anterior à década de 1990, ainda que tenha sido intensificado 
a partir daí, o que denominou de as políticas que têm um efeito "zigue-zague”. Para o autor, são três as razões que justificam esse efeito: o eleitoralismo, o experimentalismo pedagógico e o voluntarismo ideológico. O primeiro caracterizado pelas políticas educacionais que provocam "impacto" capaz de trazer resultados nas urnas. O experimentalismo pedagógico como resultante do entusiasmo com propostas elaboradas sem bases científicas, anunciadas como redentoras dos problemas educacionais e assumidas apressadamente para o conjunto da rede escolar, antes mesmo de serem suficientemente testadas. E o voluntarismo pedagógico referindo-se à atitude generosa de querer acabar com os males da educação escolar e até da sociedade como um todo, no curto espaço de uma administração, ou até em menos tempo.

Sob uma visão sistêmica, o vínculo entre educação e desigualdade social é inegável e tem consequências importantes para se pensar as estratégias políticas destinadas a enfrentar os problemas de desigualdade educacional. Não se pode pretender responder a esses desafios sem levar em consideração a questão social mais ampla. A baixa escolaridade das gerações anteriores, no caso brasileiro, é um dos fatores do baixo desempenho dos alunos. E isso é resultado de uma herança histórica, de desigualdades persistentes. As estratégias de ação para alterar esse quadro devem considerar a articulação inevitável entre políticas educacionais e a dimensão social, contemplando os processos de crescimento e desenvolvimento econômico do país. As políticas destinadas à promoção de distribuição de renda mais democrática devem contemplar a educação, mas, sobretudo, a criação e manutenção de empregos. As pressões sobre a escola são maiores quanto menos a sociedade é capaz de desenvolver outras formas de distribuição de posições sociais. Da mesma maneira como também não é possível pensar em oferecer uma educação de qualidade que permita a melhoria da inserção social das futuras gerações sem elevar os custos dessa oferta. A ampliação do financiamento da educação é ponto de partida nesta discussão. Na educação básica, a precariedade revelada nos dados sobre os docentes, as escolas e redes públicas demanda políticas imediatas que possam atuar sobre as condições objetivas e tão bem conhecidas. A baixa remuneração dos docentes, a ausência de carreiras atrativas, a infraestrutura das escolas e a reduzida carga horária dos alunos são fatores que interferem na eficiência dos sistemas e nas suas possibilidades de desenvolver maiores níveis de integração e coesão.

As mudanças no papel do Estado pretendidas pelas reformas educacionais dos anos de 1990, postulando maior desregulamentação e descentralização na gestão das políticas públicas sociais, envolvendo outros setores da sociedade, não resultaram em maior eficiência. Como afirma Tedesco (2005, p. 23), esses resultados têm promovido uma mudança de clima conceitual que permite postular estratégias baseadas em "um papel ativo do Estado" com maior legitimidade que na década de 1990. O contexto atual demanda maior coesão nacional para combater a fragmentação que 
tem caracterizado nosso sistema educacional. Promover mais coesão exige mecanismos de gestão que garantam os níveis básicos entre os diferentes entes federativos responsáveis pelos distintos níveis e pelas etapas da educação neste país. O problema central reside então na articulação entre as diferentes esferas administrativas, ou seja, na articulação de União, estados e municípios. Talvez por essa razão a constituição, ainda que tardia de um Sistema Nacional de Educação, deva ser garantida no novo PNE, cujo projeto de lei se encontra em tramitação, porém sem propor mecanismos eficazes de solução para esse problema. O projeto de lei em tramitação no Congresso, PL n. 8.035/10, não traz com a mesma força que o documento final da conAE a proposta de articulação entre os entes federativos rumo à construção de um Sistema Nacional de Educação; nesse aspecto e em muitos outros, ele se distancia do que foi acordado entre as muitas entidades que participaram ativamente da conAE e que subscreveram suas resoluções, revelando-se um projeto tímido e pouco incisivo para apontar soluções para o grande nó da educação brasileira.

A articulação entre os diferentes entes federativos não é matéria específica da educação, mas é imprescindível na sua condução. Contudo, essa articulação não pode ser dependente de arranjos governamentais, que podem oscilar de acordo com as posições políticas assumidas, as composições partidárias e outros fatores intervenientes dessas relações. As dimensões do Brasil e o desenho institucional conferido pelo sistema federativo em vigor, somados aos desafios urgentes de reduzir significativamente as desigualdades sociais e consequentemente educacionais, indicam que essa estratégia demanda políticas de Estado. É urgente pensar mecanismos de redistribuição econômica que permitam corrigir as desigualdades contrastantes entre estados, municípios e regiões do país, promovendo maior equidade na oferta educativa para que se possa pensar em construir uma escola republicana de fato.

\section{Notas}

1. A Portaria Ministerial n. 10/2008 constituiu comissão de 35 membros, a quem atribuiu as tarefas de coordenar, promover e monitorar o desenvolvimento da conAE em todas as etapas. Na mesma portaria, foi designado o secretário executivo adjunto Francisco das Chagas para coordenar a Comissão Organizadora Nacional. A Comissão Organizadora Nacional foi integrada por representantes das secretarias do Ministério da Educação, da Câmara e do Senado, do Conselho Nacional de Educação, das entidades dos dirigentes estaduais, municipais e federais da educação e de entidades que atuam direta ou indiretamente na área da educação.

2. Sobre essa discussão, publiquei um artigo intitulado "As políticas educacionais no governo Lula: rupturas e permanências", em 2009, na RBAE; ver Oliveira (2009).

3. O Plano Real foi desenvolvido como um plano de estabilização econômica pela equipe do Ministério da Fazenda na gestão de Fernando Henrique Cardoso como ministro da Fazenda do governo Itamar Franco. Seu objetivo foi controlar a hiperinflação para pôr fim a quase três décadas de inflação elevada, o que implicou a substituição da antiga moeda para o real, a partir de $1^{\text {o }}$ de julho de 1994.

4. Cf. Ball (2002) e Anderson (2002). 
5. Como exemplo, destacam-se os seguintes programas: Bolsa Família e projovem, prouni, entre outros.

6. O PISA é um programa internacional de avaliação comparada, cuja principal finalidade é produzir indicadores sobre a efetividade dos sistemas educacionais, avaliando o desempenho de alunos na faixa etária dos 15 anos, idade em que se pressupõe o término da escolaridade básica obrigatória na maioria dos países. Esse programa é desenvolvido e coordenado internacionalmente pela ocDE, havendo em cada país participante uma coordenação nacional. No Brasil, o PISA é coordenado pelo Instituto Nacional de Estudos e Pesquisas Educacionais Anísio Teixeira (INEP).

7. Disponível em: <www.mec.gov.br/notícias>

8. Segundo depoimento do próprio ministro, em 2008, os 5.563 municípios brasileiros aderiram ao Compromisso, comprometendo-se a atingir metas como a alfabetização de todas as crianças até, no máximo, 8 anos de idade.

9. Cf. dados da PNAD (2008).

\section{Referências}

ANDERSON, G.L. Hacia uma participación auténtica: desconstrucción de los discursos de las reformas participativas em educación. In: NARodowsKI, M. (Org.). Nuevas tendências em políticas educativas: Estado, mercado y escuela. Buenos Aires: Granica, 2002. p. 145-200.

BALL, S.J. Grandes políticas, un mundo pequeño: introducción a una perspectiva internacional em las políticas educativas. In: NArodowski, M. (Org.). Nuevas tendências em políticas educativas: Estado, mercado y escuela. Buenos Aires: Granica, 2002. p. 103-128.

BRASIL. Conferência Nacional de Educação (CONAE), dez. 2008, Brasília, DF. Documento-referência: Construindo o Sistema Nacional Articulado de Educação: O Plano Nacional de Educação, Diretrizes e Estratégias de Ação. Brasília, DF, 2008.

BRASIL. (Constituição 1988). Constituição da República Federativa do Brasil; promulgada em 5 de outubro de 1988. Vade Mecum. 3. ed. São Paulo: Saraiva, 2007.

BRASIL. Lei n. 9.394, de 20 de dezembro de 1996. Estabelece as diretrizes e bases da educação nacional. Diário Oficial da União, Brasília, DF, 24/12/1996.

BRASIL. Lei n. 9.424, de 24 de dezembro de 1996. Dispõe sobre o Fundo de Manutenção e Desenvolvimento do Ensino Fundamental e de Valorização do Magistério - FUnDEF. Díario Oficial da União, Brasília, DF, 26/12/1996.

BRASIL. Lei n. 10.836, de 9 de janeiro de 2004. Instituiu o Programa Bolsa Família, destinado às ações de transferência de renda com condicionalidades. Diário Oficial da União, Brasília, DF, 12/01/2004.

BRASIL. Lei n. 11.129, de 30 de junho de 2005. Instituiu o Programa Nacional de Inclusões de Jovens - Projovem. Programa emergencial e experimental, destinado a 
executar ações integradas que propiciem aos jovens brasileiros, na forma de curso previsto no art. 81 da Lei n. 9.394, de 20 de dezembro de 1996, elevação do grau de escolaridade visando à conclusão do ensino fundamental. Diário Oficial da União, Brasília, DF, 01/07/2005.

BRASIL. Lei n. 11.494, 20 de junho de 2007. Regulamenta o Fundo de Manutenção e Desenvolvimento da Educação Básica e de Valorização dos Profissionais da Educação - FUNDEb. Diário Oficial da União, Brasília, DF, 21/06/2007.

BRASIL. Ministério da Educação. O ensino que dá certo: a caravana da educação. Brasília, DF: MEC, 2008.

BRASIL. Projeto de Lei n. 8035/2010. Aprova o Plano Nacional de Educação para o decênio 2011-2020 e dá outras providências. Brasília, DF, 2010.

CUNHA. L.A. Educação, Estado e democracia no Brasil. São Paulo: Cortez; Rio de Janeiro: FLACso do Brasil, 1991.

DUBET, F. Mutaciones institucionales y/o neoliberalismo?. In: Tenti Fanfani, E. Governabilidad de los sistemas educativos en América Latina. Buenos Aires: IIPE; UnEsco, 2004.

DUBET, F.; DURU-BELLAT, M.; VÉRÉTOUT, A. Les sociétés et leur école: emprise du diplôme et cohésion sociale. Paris: Seuil, 2010.

FERNANDES, F. Dominación y desigualdad: el dilema social latinoamericano. Bogotá: Siglo del Hombre; clacso, 2008.

OLIVEIRA, D.A. As políticas educacionais no governo Lula: rupturas e permanências. RBPAE, v. 25, n. 2, p. 197-209, maio/ago. 2009.

OLIVEIRA, D.A. Educação básica: gestão do trabalho e da pobreza. 2. ed. Petrópolis: Vozes, 2010.

SADEK, M.T. O pacto federativo em questão. Revista Brasileira de Ciências Sociais, São Paulo, v. 15, n. 42, p. 153-154, fev. 2000.

TEDESCO, J. Como superar la desigualdad y la fragmentación del sistema educativo argentino? Buenos Aires: IIPE; UnesCo, 2005.

Recebido em abril de 2011.

Aprovado em maio de 2011. 